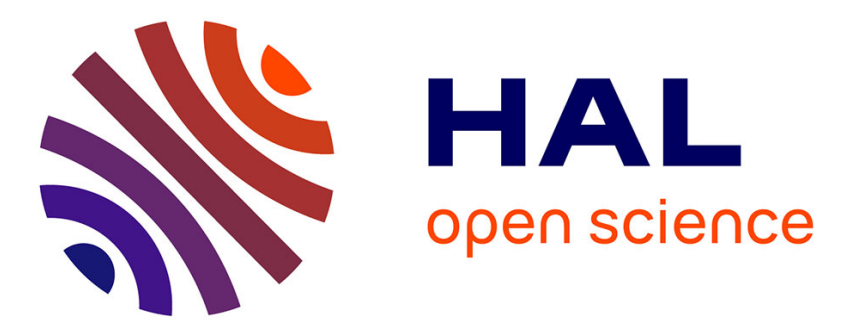

\title{
XAFS, IR, Raman and UV-Vis Characterization of Framework Ti(IV) Species in Ti-Silicalites
}

C. Lamberti, S. Bordiga, A. Zecchina, G. Vlaic, G. Tozzola, G. Petrini, A. Carati

\section{- To cite this version:}

C. Lamberti, S. Bordiga, A. Zecchina, G. Vlaic, G. Tozzola, et al.. XAFS, IR, Raman and UV-Vis Characterization of Framework Ti(IV) Species in Ti-Silicalites. Journal de Physique IV Proceedings, 1997, 7 (C2), pp.C2-851-C2-853. 10.1051/jp4:1997257 . jpa-00255340

\section{HAL Id: jpa-00255340 https://hal.science/jpa-00255340}

Submitted on 1 Jan 1997

HAL is a multi-disciplinary open access archive for the deposit and dissemination of scientific research documents, whether they are published or not. The documents may come from teaching and research institutions in France or abroad, or from public or private research centers.
L'archive ouverte pluridisciplinaire HAL, est destinée au dépôt et à la diffusion de documents scientifiques de niveau recherche, publiés ou non, émanant des établissements d'enseignement et de recherche français ou étrangers, des laboratoires publics ou privés. 


\title{
XAFS, IR, Raman and UV-Vis Characterization of Framework Ti(IV) Species in Ti-Silicalites
}

\author{
C. Lamberti, S. Bordiga, A. Zecchina, G. Vlaic*, G. Tozzola**, G. Petrini** and A. Carati*** \\ Dipartimento di Chimica I.F.M., Via P. Giuria 7, 10125 Torino, Italy \\ * Dipartimento di Scienze Chimiche e Sincrotrone Trieste SCpA, Trieste, Italy \\ ** ENICHEM SpA, Centro di Ricerche di Novara, Via G. Fauser 4, Novara, Italy \\ *** ENI RICERCHE, Via F. Maritano 26, 20097 S. Donato (Mi), Italy
}

\begin{abstract}
The main results obtained by using IR, Raman and UV-Vis techniques concerning the structure of the $\operatorname{Ti}(\mathrm{IV})$ center in Ti-silicalite is briefly reviewed and discussed with recent XAFS results. The Ti(IV) is in tetrahedral coordination in vacuo and expands its coordination sphere upon interaction with adsorbates. Present EXAFS results indicate, for the dehydrated sample, a first shell coordination number higher then four $(4.45 \pm 0.3)$, suggesting, in a fraction of sites, the substitution of a bridged oxygen with two $\mathrm{OH}$ groups.
\end{abstract}

\section{INTRODUCTION}

Ti-silicalite is a zeolitic catalyst very active in selective oxidation reactions utilizing $\mathrm{H}_{2} \mathrm{O}_{2}$ as oxidant [1] and many attempts have been made to characterize the structure of Ti(IV) centers. For the time being the most common view is that Ti (IV) is incorporated as isolated center into the framework and is occupying a substitutional tetrahedral position. In favor of this hypothesis an impressive number of results have been accumulated, based on XRD, UV-Vis, XANES, XPS, IR, Raman and EPR [2-13] spectroscopies.

Many problems and questions however are still open. Among all we will mention the following four: i) if the key point of the catalytic activity is related to the local fourfold coordination of Ti(IV) only, why is the same activity not shown by diluted TiO ${ }_{2}$ $\mathrm{SiO}_{2}$ systems (the only apparent difference being represented by the amorphous nature of the hosting solid)? The question is not trivial, since $\mathrm{TiO}_{2}-\mathrm{SiO}_{2}$ glass is containing tetrahedral Ti(IV) are indeed known [14]. ii) what is the role of the zeolitic structure? Is it merely acting as a crystalline high surface area, tetrahedral hosting structure, or there is some other effect associated with its tridimensionally organized array of intersecting channels? iii) how is the Ti(IV) center structure modified in presence of adsorbates and how is the framework accommodating the inevitable relaxation effects associated with the adsorption of molecules on the fourfold coordinated Ti(IV)? iv) how stable to hydrolysis are the Ti-O-Si bridges which are linking the Ti(TV) to the framework? From these four examples we can conclude that the need to know in greatest detail the structure of the Ti(IV) before and after interaction with adsorbate is still a vital problem.

\section{EXPERIMENTAL}

XAFS spectra have been performed in the transmission mode, at the EXAFS3 beam line of LURE in Orsay (F), using air filled ionization chambers for both incident and transmitted beams. Incident beam was monochromatized using a double crystal $\mathrm{Si}$ (311) for XANES spectra (sampling step: $0.3 \mathrm{eV}$ ) and a double crystal Si(111) for EXAFS spectra (sampling step: $2.0 \mathrm{eV}$ ). In both cases the energy/angle calibration was performed using a Ti foil and crystals were detuned up to $1 / 2$ of the rocking curve to avoid harmonics. EXAFS analysis was performed following standard procedures [15] using Michalovicz programs [16]. Each EXAFS spectrum was acquired three times under the same experimental conditions and extracted $\chi(k)$ have been averaged before the EXAFS data analysis. Standard deviation calculated from the averaged spectra was used as an estimate of the statistical noise for the evaluation of the error associated with each structural parameters.

\section{RESULTS AND DISCUSSION}

For sake of clarity let us summarize first the most relevant results deriving from IR, Raman, UV-Vis and XANES spectroscopies. The $960 \mathrm{~cm}^{-1}$ peak appearing in both IR (see Fig. 1, full line curve) and Raman spectra [3,4,10] is assigned to a mode with stretching character of the complex group of atoms shown in schemes la and $1 \mathrm{~b}$. which can be viewed as the $v_{a s}$ of the (SiOTi) primary unit or as the $v_{a}$ of the $\left(\mathrm{SiO}_{4}\right)$ unit adjacent to the Ti(IV). Due to the higher mass of $\mathrm{Ti}$ (with respect to the $\mathrm{Si}$ ) and to the polarized character of the Ti-O bond, the $v_{\text {s }}$ of the (SiOTi) unit has primarily a $v$ (Si-O) stretching character and hence it can be considered essentially as the $v(\mathrm{Si}-\mathrm{O})$ mode perturbed by the presence of framework $\mathrm{Ti}$ species. We can see, from this, that the differences between the views based on the spectroscopic properties of the (SiOTi) and ( $\left.\mathrm{SiO}_{4}\right)$ building units is only apparent. This band thus represent the direct proof that Ti atoms are framework species substituting Si in tetrahedral sites. 
<smiles>C=[Si](C)O[Si](O[Si](C)(C)C)(O[Si](C)(C)C)O[Si](C)(C)C</smiles>

Scheme 1a

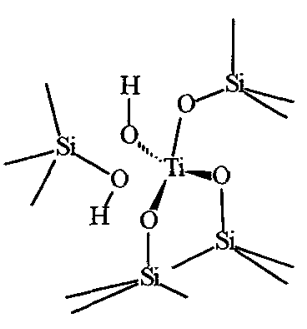

Scheme $1 b$

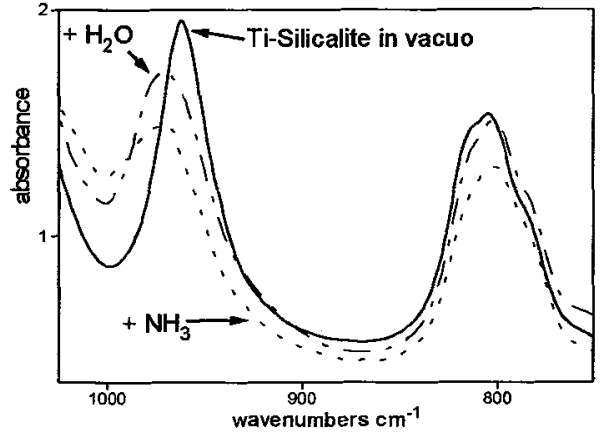

Figure 1: IR spectra, in the framework stretching mode, of $\mathrm{T}^{-}-$ silicalite: effect of interaction with ligands.

The UV-Vis spectra of Ti-silicalite in vacuo is also very informative about the fourfold coordination of the Ti, since the band at $48.000 \mathrm{~cm}^{-1}$ can only be explained in terms of charge transfer transition of isolated and fourfold coordinated Ti species $[4,7,9]$. The same conclusion is reached by XANES (compare first and second spectra from top in Fig. 2) because the narrow peak at $4967 \mathrm{eV}$ can be only explained in terms of the Laporte allowed $A_{1} \rightarrow E$ transition of the $(1 \mathrm{~s})^{2} \rightarrow(1 \mathrm{~s})^{1}(3 \mathrm{~d})^{1}$ excitation in tetrahedral and nearly tetrahedral structures [7-9]. The previous assignments are also based on the behavior of the $(1 \mathrm{~s})^{2} \rightarrow(1 \mathrm{~s})^{1}$ (3d) transitions upon $\mathrm{NH}_{3}$ dosage. In particular the effect of ligands $\left(\mathrm{NH}_{3}\right.$ and $\left.\mathrm{H}_{2} \mathrm{O}\right)$ on the IR (see Fig. 1) UV-Vis and XANES (see Fig. 2) spectra, show clearly that the coordination sphere of Ti(IV) expand upon interaction with $\mathrm{NH}_{3}$. In fact the IR band at $960 \mathrm{~cm}^{-1}$ is blue-shifted in energy, decreased in intensity and broadened (see Fig. 1). This indicates that the perturbation effect caused by Ti species to the framework stretching modes is decreased. Moreover a new ligand $\left(\mathrm{NH}_{3}\right.$ or $\mathrm{H}_{2} \mathrm{O}$ ) to metal Ti(IV) charge transfer band appears in the UV [7-9] and the XANES spectra becomes more similar to that characteristic of a sixfold (quasi octahedral) species (compare third and fifth spectra from top in Fig. 2). Adsorption of $\mathrm{NH}_{3}$ is partially reversible upon prolonged outgassing at room temperature (compare second, third and fourth spectra from top in Fig. 2). All these facts are consistent with an expansion of the sphere of Ti(IV) centers through ligand coordination, as described in the following scheme:<smiles>CO[Al](OC)(OC)OC</smiles><smiles>[Z][Te]([3H])(OC)(OC)OC</smiles>
and/or<smiles>[Y][Te]([Y])(O)(OC)OC</smiles>

\section{Scheme 2}

The conclusions reached on the basis of the previous observations are not univocal. In fact they are valid also for the structures generated by hydrolysis of one of the TiOSi bonds (see scheme 1 structure b, where the Ti is still fourfold coordinated but where a bridging oxygen has been substituted by two hydroxyls groups). As these species can play a very relevant role in catalysis, for instance in the formation of hydroperoxydic species by interaction with $\mathrm{H}_{2} \mathrm{O}_{2}$, it is necessary to determine in detail the number of nearest neighbors of Ti(IV) (which is 4 in structure la and 5 in structure 1b). EXAFS is the ideally designed technique to answer this question. In a previous EXAFS study [7] carried out at the PULS beamline of Frascati National Laboratories the coordination number of Ti(IV), in absence of weakly adsorbed water molecules was found to be slightly larger than four (4.4 \pm 0.6). However as the associated error bar was \pm 0.6 a clear conclusion about this point was not possible.

In the present work, we present EXAFS data collected using the higher photon flux available at the DCI storage ring at LURE, see experimental, and we report results characterized by error bars reduced by a factor two. Fig. 3a shows the averaged $k \chi(k)$ function obtained estimating the atomic contribution by a polynomial fit (fifth degree) and then subtracted from experimental data following the procedure proposed by Lengeler and Eisenberger [17] (pre-edge was modeled with a line). By a simply comparison with experimental $\mathrm{k} \chi(\mathrm{k})$ reported in Fig. 6 of ref. [7a] the improvement of the signal/noise ratio is evident, being now the fourth oscillation, at about $9-11 \AA^{-1}$, clearly visible. Fig $3 b$ reports the $\mathbf{k}^{3}$ weighted FT computed in the range 3.4-12.1 $\AA^{-1}$ using a Kaiser window with $\tau=2.5$ (no phase correction has been adopted). Data analysis were obtained in the frame of single scattering curved wave approximation extracting the experimental phase shift and amplitude functions from anatase model compound ( 6 nearest-neighbor at $1.95 \AA$ ). The first shell contribution was then filtered in the range $0.91-1.98 \AA$ and modeled as Ti-O coordination shell, resulting in a first coordination shell formed by $4.45 \pm 0.3$ oxygen atoms at $1.805 \pm$ $0.008 \AA$. The quality of the fit, reported in Fig. $3 \mathrm{c}$ is much better than that reported in Fig. 8 of ref. [7a]. From Fig $3 \mathrm{~d}$, the symmetry of the imaginary part with respect to the modulus of the phase corrected FT is noticeable [18]. The here presented results strongly suggest that, even in the dehydrated sample, both structures depicted in schemes $1 \mathrm{a}$ and $1 \mathrm{~b}$ are present. This result is in agreement with previous IR, Raman and UV-Vis data from our group $[7,9,10]$ and with very recent NMR and XAFS results from ref. [13]. The important and helpful assistance of F. Villain is gratefully acknowledged. 


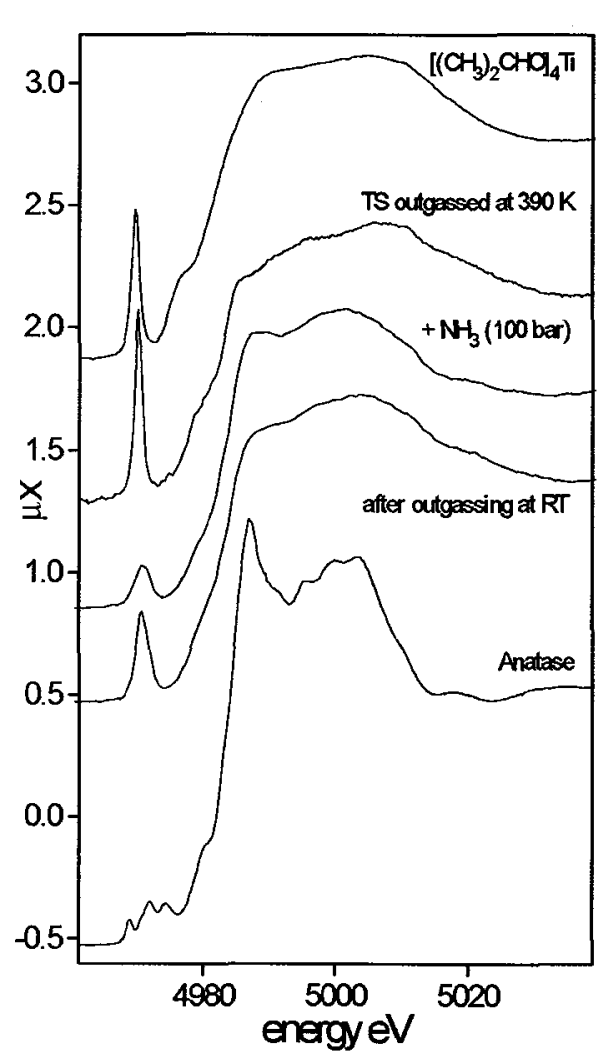

Figure 2: XANES spectra of Ti(IV) in different environements, from top to bottom: $\left[\left(\mathrm{CH}_{3}\right)_{2} \mathrm{CHO}\right]_{4} \mathrm{Ti}$; Ti-silicalite in vacuo, after interaction with $\mathrm{NH}_{3}$ and subsequent evacuation at RT; anatase.
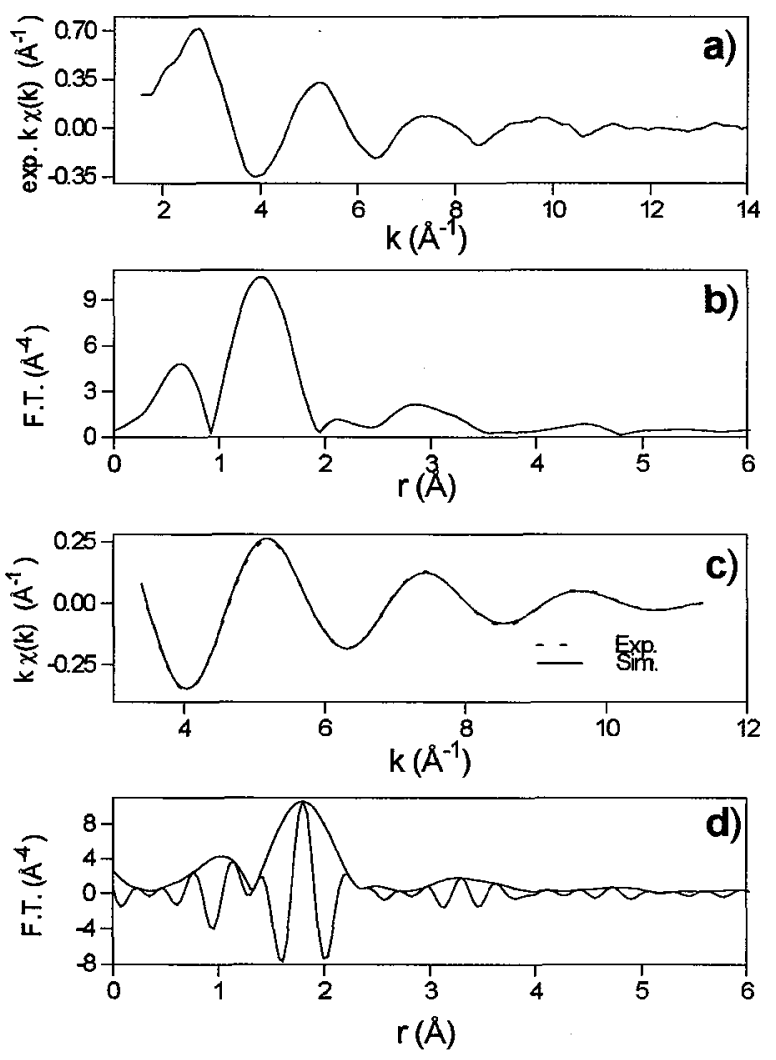

Figure 3: a) Experimental $k \chi(k)$; b) $\mathrm{k}^{3}$ weighted $\mathrm{FT}$ in the range 3.4-12.1 $\AA^{-1}$ without phase correction; c) corresponding back-FT in the 0.91-1.98 $\AA$ (dashed line) and best fit (full line); e) modulus and imaginary part of the phase corrected $\mathrm{k}^{3}$ weighted FT of $\chi(\mathrm{k})$ in the range 4.4-12.1 $\AA^{-1}$.

\section{References}

[1] Bellussi G., Carati A., Clerici G. M., Maddinelli G. and Millini R., J. Catal. 133 (1992) 220-230.

[2] Boccuti M.R., Rao K.M., Zecchina A., Leofanti G. and Petrini G., Stud. Surf. Sci. Catal. 48 (1989) 133-144.

[3] Zecchina A., Spoto G., Bordiga S., Padovan M., Leofanti G. and Petrini G., Stud. Surf. Sci. Catal. 65 (1991) 671-680.

[4] Zecchina A., Spoto G., Bordiga S., Ferrero A., Petrini G., Padovan M., Leofanti G., Stud. Surf. Sci. Catal. 69 (1991) $251-258$.

[5] A. Zecchina, et al., in New Frontiers in Catalysis, L. Guczi et al., Eds., Elsevier, Amsterdam (1993) 719-729.

[6] Geobaldo F., Bordiga S., Zecchina A., Giamello E., Leofanti G. and Petrini G., Catal. Lett. 16 (1992) 109-115.

[7] Bordiga S. et al., J. Phys. Chem. 98 (1994) 4125-4132; Catal. Lett. 26 (1994) 195-208.

[8] Bordiga S. et al., Nucl. Instr. Meth. B 97 (1995) 23-27.

[9] A. Zecchina, Bordiga S., Lamberti C. Ricchiardi, G., Scarano D., Petrini, G. Leofanti G., Mantegazza M, Catal. Today in press.

[10] Scarano D. et al., J. Chem. Soc. Faraday Trans. 89 (1993) 4123-4130.

[11] Trong On D., Bittar A., Sayari A., Kaliaguine S., Bonneviot L., Catal. Lett. 16 (1992) 85-95; J.Mol. Catal. 74 (1992)233-236

[12] Bonneviot L., Trong On D. and Lopez A., J. Chem Soc. Chem. Commun (1993) 685-687.

[13] Le Noc L et al., Stud. Surf. Sci. Catal. 101 (1996) 61 1-620; ibid. 97 (1995) 19-25; C. Cartier et al., Physica B 208\&209 (1995) 653-654.

[14] Emili M., Incoccia L, Mobilio S., Fagherazzi G. and Guglielmini M. J. non Cryst. Solids 74 (1985) 129-137.

[15] Lytle F. W., Sayersand D. E. and Stern E. A., Co-Chairmen, Physica B 158 (1989) 701-722.

[16] Michalovicz A., Ph.D. thesis, Université Paris Val de Marne 1990.

[17] Lengeler, B. and Eisenberger, P., Phys. Rev. B 21 (1980) 4507-4517.

[18] Lee P. A.and Beni G., Phy. Rev. B 15 (1977) 2862-2883. 